\title{
Life Transition for the Emerging Adults and Their Mental Health
}

\author{
Jin Kuan Kok
}

\begin{abstract}
Emerging adults have been conceptualized as a developmental stage which is full of uncertainty and ambiguity. And the mental health issues among this group of emerging adults are worrying as there was a prevalence of depression found from this group of young people in Malaysia. This study aims to investigate a group of emerging adults who have gone through depression to understand their experience going through depression. A snowball sampling method was employed and in-depth interviews were conducted with eight research participants aged 18-24 who suffered from depression but were on their way of recovery. An interpretative phenomenological analysis was carried out for data analysis. The triggering events were inability to cope with transition from high schools to universities or transition from being single to having intimate relationships, and also issue like loved one being diagnosed as having cancer. The findings reveal challenges faced during this transitional stage especially experience of rejection. The recovery stage involves reflection, supports from the psychosocial context and religious guidance. This research highlights the vulnerability of transitional stage of emerging adults in highly industrialized or post-industrialized countries.
\end{abstract}

Index Terms-Emerging adults, mental health, depression, life transition, Malaysian youth.

\section{INTRODUCTION}

It is observed that the young adults in the past generation between the age of 18 and 20 were more aware of their social roles and responsibilities that were inherent to them. For example, they would get married and take on the responsibilities as other adults by setting up their own family. It has also been identified that the stage of late adolescents and emerging adults was not available to them as the transition from adolescence to adulthood was brief. Late adolescents and emerging adulthood are new concepts of developmental periods due to social changes. As most of the modern young adults, they are obligated to attend colleges or universities to pursue their higher education and opportunities for exploring their individual life are made available more than the generations of the past.

Although there is opportunity for the young adults in exploring their studies, career, love relationship and other possible life directions, they are also susceptible to the vulnerability of coping with the transitional changes for the extended period that they have. Arnett [1] conceptualized

Manuscript received May 26, 2014; revised August 28, 2014. This work was supported by the UTAR Research Fund (UTARRF). Project no. IPSR/RMC/UTARRF/2012-C2/K04.

J. K. Kok is with the Department of Psychology \& Counselling, Faculty of Arts \& Social Science, Universiti Tunku Abdul Rahman, Kampar Campus Malaysia (e-mail: kokjk@utar.edu.my). emerging adults as full of ambiguity and uncertainty. He also characterized the young emerging adulthood as a distinct period of development with many unpredictable variables and diversity especially when they start to pursue college or university education and enter new relationships. There was also found that there is higher number of female adolescents suffered depression due to romantic relationships and the negative experience in romantic relationship during adolescents was identified to be stressful and had many detrimental effects [2], [3]. Therefore, there is a prevalence of depression among the young adolescents, especially for girls who involve in romantic relationship. Arnett [1] also found many risk behaviours happened during emerging adulthood, and the effects of vulnerability may be different among genders [4], [5].

Besides, it has also been identified that the high suicide rate among the young adolescents is related to academic performance [6]. For instance, most parents in Malaysia especially among the Chinese who have been putting much emphasis on academic performance of their children. This is because the mentality among the Chinese in Malaysia has been influenced by traditional Confucius values which place high importance on education, not only for building characters as the foundation of the knowledge, but also a tool for upward mobility. Thus, tertiary education seems to be viewed as an opportunity for the young adolescents to learn how to be independent for themselves. For example, staying in hostel or the residential area near the college or university will be less dependent from the surveillance of the parents.

Due to the extended opportunity for exploring both the studies and love relationships, it also comes with the rising incidence of depression rates among the young adults in Malaysia. Therefore, this study aims to investigate the young adolescents whose age between 18 and 24 (emerging adults), who suffered from depression but on the route of recovery to find out their struggles during this life stage and also to understand their recovery journey.

\section{LITERATURE REVIEW}

Erikson [7] initialed various stages of human development in which emerging adulthood was not included. In fact, the adolescent stage discussed by Erikson has been extended due to social changes. Arnette [1] added the stage of 'emerging adulthood' and he holds that similar to adolescent stage, this emerging adulthood is culturally constructed, and it is not universally applicable. Young people in Nigeria, Morocco and India for instance will have different life experience. Hall' view [8] of adolescence was from the age of 14 to 24 (which was different from some of the contemporary 
researchers who generally hold that adolescence begins at 10 or 11 and ends by 18 or 19). Therefore this emerging adult stage is considered a post-adolescence stage. However, most people age 18 to 24 disagreed with being labeled as adolescents, but they also would not agree that they were fully adults [1]. Only when individuals attain financial independence, becoming self-sufficient and accepting responsibility for one's self and making independent decisions, then they will transit to adulthood successfully [1]. However, the above conceptualization is basically from a western individual society where individualistic transitions are emphasized [9].

The percentage of Malaysian young people aged 20 years and above with tertiary education has increased from 16.0 percents in 2000 to 21.6 percents in 2010 [10]. This trend was also observed for all ethnics groups in Malaysia. Although Malaysia is still a developing country, the demographic profile of our young people are similar to that of industrial countries, $17 \%$ of the population who belong to the age group of $15-25$ are still attending schools or tertiary education, and the youth dependency ratio is 38.1 [10].

Although the age of getting married in Malaysia did not show a delay, according to a comparison study of Census 2000 and 2010 on mean age at first marriage of Malaysian citizens: the mean age for the males decreased from 28.7 years to 28 years; while for the females, it increased from 25.1 years to 25.8 years. However, it was reported that more than 2.5 millions of Malaysian youth whose age are 25 and above still enjoy their single life for the reasons of financial issues and career advancements [11].

For this group of emerging adults, there was a prevalence of depression found [12]. The National Health and Morbidity Survey III (NHMS III) reported that young Malaysians in the 16- 19 year and the $20-24$ year age group had a higher prevalence of psychiatric morbidity $(14.4 \%$ and $12.1 \%$, respectively) compared to other age groups [13]. The study also found that youth aged 16-24 years old had the highest prevalence of acute and chronic suicidal ideation (10\% and $26 \%$, respectively), a symptom that typically associated with depression, compared to other age groups. Similarly, the National Health and Morbidity Survey 2011 found the 16 24 year age group had the highest prevalence rate of both current $(2.5 \%)$ and lifetime (3.1\%) major depressive disorder [13]. On the other hand, a recent study among university students revealed a much higher prevalence rate of depression, with $37.2 \%$ of students (18 - 24 years old) were experiencing at least a moderate level of depression. It was also reported that those aged 16-25 as being the highest risk group [13]. Wong [14] connected the high suicide rate in Malaysia to the diminishing traditional protecting factors where normative restraint has been disrupted by various social changes.

The above statistics leave a bewildering impression to most adults and educators. What happened to our young people ? What challenges or difficulties faced that have affected their mental health status? How do the unpredictability and vulnerability of the emerging adulthood relate to the depression experienced by our young people? By having this study the researcher hopes to better understand the thoughts and feelings of our young people going through changes or transition in life.

\section{METHODS}

TABLE I: RESEARCH PARTICIPANTS

\begin{tabular}{|c|c|c|}
\hline Participants & Life experience & Issues \\
\hline Ms A Chinese & $\begin{array}{l}\text { She found it difficult to adapt to the } \\
\text { new environment in the university: } \\
\text { everything was new and challenging to } \\
\text { her: classmates were very competitive, } \\
\text { the laboratory work was not what she } \\
\text { expected. She then developed panic } \\
\text { attacks. Being rejected twice by her } \\
\text { boy friend made her situation worse. }\end{array}$ & $\begin{array}{l}\text { Transistion to } \\
\text { university }\end{array}$ \\
\hline Ms B Indian & $\begin{array}{l}\text { She felt she was a victim in her family } \\
\text { as she was not welcomed when her } \\
\text { parents expected her to be a boy; being } \\
\text { a middle child and raised by a capable } \\
\text { single mother who works as a doctor, } \\
\text { she yearned for attention and love but } \\
\text { couldn't get it. She attempted to } \\
\text { commit suicide even she scored } \\
\text { straight As for her PMR. She felt life } \\
\text { has no meanings at all. }\end{array}$ & $\begin{array}{l}\text { Academic stress } \\
\text { and family } \\
\text { issues. }\end{array}$ \\
\hline Ms C Chinese & $\begin{array}{l}\text { She couldn't accept the loved ones in } \\
\text { her life suffered from breast cancer. } \\
\text { While worrying losing her loved ones, } \\
\text { she become depressed, lack of energy } \\
\text { to face ordinary life. }\end{array}$ & $\begin{array}{l}\text { Transistion to } \\
\text { university. }\end{array}$ \\
\hline Mr D Chinese & $\begin{array}{l}\text { He was heartbroken when rejected by } \\
\text { his girl friend. He kept his school life, } \\
\text { and did his school work but he would } \\
\text { cried almost every night for nearly half } \\
\text { a year, and even attempted suicide. He } \\
\text { couldn't accept being rejected. }\end{array}$ & $\begin{array}{l}\text { Rejected by girl } \\
\text { friend. }\end{array}$ \\
\hline Mr E Chinese & $\begin{array}{l}\text { He was sent to a new tuition centre and } \\
\text { being bullied the students from the } \\
\text { centre. He experienced being looked } \\
\text { down and scolded or punished by the } \\
\text { school teachers without good reasons. } \\
\text { He felt death could be a solution. } \\
\text { When he was } 17 \text {, he was rejected by } \\
\text { the girl he liked. }\end{array}$ & $\begin{array}{l}\text { Rejected by girl } \\
\text { friend. }\end{array}$ \\
\hline Mr F Indian & $\begin{array}{l}\text { He reported being cheated by his girl } \\
\text { friend who always made use of him. } \\
\text { His girl friend exploited his money and } \\
\text { used it on another boy. He was upset } \\
\text { and thought of committing suicide so } \\
\text { that his girl friend would feel guilty. }\end{array}$ & $\begin{array}{l}\text { Cheated by his } \\
\text { girl friend. }\end{array}$ \\
\hline Mr G Chinese & $\begin{array}{l}\text { When he got his examination results, } \\
\text { he was not able to cope because it was } \\
\text { really difficult for him to accept } \\
\text { failure. Suddenly he felt life was } \\
\text { meaningless and he wished to die. He } \\
\text { attempted cutting himself and he } \\
\text { locked himself for a week in his room. }\end{array}$ & $\begin{array}{l}\text { Coping with } \\
\text { poor academic } \\
\text { results. }\end{array}$ \\
\hline Ms H Chinese & $\begin{array}{l}\text { She was not close with her parents as } \\
\text { she was raised by hergrandmother. } \\
\text { Felt like she doesn't belong to anyone } \\
\text { and she yearns for love and cares. He } \\
\text { secondary school and university } \\
\text { results were good, but she always felt } \\
\text { empty and there was once, she was } \\
\text { depressed and felt like committing } \\
\text { suicide. }\end{array}$ & $\begin{array}{l}\text { Felt } \\
\text { meaningless } \\
\text { even though she } \\
\text { scored well in } \\
\text { examination. }\end{array}$ \\
\hline
\end{tabular}

A qualitative research method was employed. Snowball sampling was used. Advertisement was put on Facebook and students from a university responded and they introduced their friends who had gone through depression experience. 
Eight research participants aged $18-24$ were recruited.

In-depth interviews were conducted. All of the participants was diagnosed with depression when they were 14-18 while they were still in secondary schools or at the first year of university. Most of them were either recovered or on their ways of recovery at the time of interviewed. Only two of them were still on medication.

The participants were asked to share their life experience (what happened to them and what was their thinking and feeling when they were depressed, and how did they recover?). All interviews were taped and transcripted with permission. An Interpretive phenomenological analysis (IPA) was used for data analysis. Interpretive phenomenological analysis developed by Smith [15] aims to draw out the first-person account to better understand their life experience

\section{FINDINGS}

\section{A. Triggering Events: Transitional Stage}

Almost all of the triggering events happened during transitional stage of life: either transition from high schools to universities or transition from singlehood to having intimate relationship. This is a transitional stage when many challenges were faced as the participants needed to adapt new environment, new set of friends, new intimate boy-or girl friend, and new rules and regulation from the new setting.

Ms. A got a good offer of a popular course from a local university, but she was not able to cope. She copied work from her classmates but she couldn't understand. She started crying without reasons and she loathed herself and she did not know what she was doing.

"I was all alone, I was admitted to a popular course, but it was in Kelantan. I went there alone, everything was new. I'm very introverted and it was very hard to get new friend. I felt extremely lonely Most of my classmates scored CGPA of 3.8 and above but I only scored 3.3."

Besides transition to new environment, participants were also at a stage entering new relationships.

Mr. G felt extremely lonely when he entered tertiary education. He left behind his good friends and found it difficult to make new friends.

"I thought I was very intelligent as I scored well in my secondary school. Therefore, when I received negative comments from my new course-mate and lecturer, I felt terribly negative. I didn't have close friends when I first came to university."

\section{B. Triggering Events: Being rejected}

It was found that the depression was triggered by rejection.

As an emerging adult, involvement in intimate relationships is common. Most of the participants experienced being rejected by their girl friend or boy friend and they felt being "dumped".

In Mr. F's case, he felt his heart was broken and it was so painful that he could bear no longer when he found his girlfriend cheated and betrayed him by going out with another man. He was very angry but he was kind not to take revenge.
"I become an ATM for her to take money, but she went out with the other guy."

As for Ms. A, her suicide attempts happened when her boyfriend rejected her. She yearned to continue the relationship but it did not work. Her boy friend even blamed her for what happened. She felt there was no hope. She couldn't accept and was not in a rational state to think so she had attempted suicide twice.

"That time we had already broke up, but then he wanted to try again to see if we could still be together. It was like he gave me hope but he took the hope away from me, because after we parted he smsed me that we couldn't be together and it was the end of it. So, it was like the end of what I had hoped for and everything seemed meaningless for me. What is the point and what for to continue living?"

In Mr. E's case, he felt really hurtful and shameful as each time he had worked very hard but a few relationships he has had did not turn out as expected. He felt that it was unfair as other people always had good intimate relationship while he always got rejection.

"I posted suicide notes on Facebook, as I felt it was the end of my life. Many friends response and tried to comfort me."

\section{Triggering Events: Coping with Loved One's Cancer}

Ms $\mathrm{C}$ became depressed when she was frightened by the seemingly uncured disease, cancer. She was afraid to lose her loved ones. Both her mum and her supervisors were diagnosed with cancer. She started reading up about cancer and she found that even going through chemotherapy, the chances of relapse were high. Started from excessive worrying, she developed anxieties and finally depression.

Ms C" What is the point of living? Life has no meaning at all. You will die one day. So , why study?”

\section{Recovery and Reflection}

Psychosocial supports was found to be important as it served as a source of support. Ms A mentioned her family took her to see a psychiatrist and she was hospitalised once and was put on medication. She had three suicide attempts and was trying to put a stop to her unbearable pain. Later when she recovered, she attributed her immaturity of handling rejection in relationship.

"I didn't know what I was doing. I couldn't help absorbing what other people talked about me. My boy friend said I was negative and I had lots of negative energy. I totally believed him until I really hated myself that I wished myself dead and only death could put a stop to the pain I was going through" Upon reflection, she understands that she was immature in her thinking and she should not have believed what he said. "I realised later that he was lying to me, and what he said about me was all wrong, but at that time, I didn't know".

Educators have explained the high rate of depression among teenagers is largely due to a lack of fully mature response inhibitory neural networks because the development of the prefrontal cortex, responsible for logical 
reasoning, is still developing [16]. Besides, negative life events for adolescents contributed to the mental health status [17].

Being rejected was painful, here are some reflections after recovery from broken relationship.

"I thought I have become a better person. Next time I will be able to make effort to make it works for me. Although every time I was the one being rejected. Next time I won't hurt another person in the same way, may be I will try to explain so that there will be understanding, instead of hurt and pain" (Mr E).

"I got inspiration from my cousin. He has gone through loved ones passed away and he was really devastated. If he can stand up again and can have a good marriage later, I think I will be able to have a happy life too" (Mr D).

\section{E. Religious Guidance}

A number of our participants mentioned religion has provided guidance for them.

Ms A become a Christian later after her two suicide attempts and she sought supports from the Christian community. Ms B is a Muslim and she was prohibited from attempting suicide. Ms $\mathrm{C}$ joined community activities organized by Buddhist society. Mr. G read about the teaching of next life from Buddhist belief, and he suddenly become more aware of the meaning in life. This has strengthened him to be more able to cope with the challenges faced and become more positive towards life.

\section{DISCUSSION}

Depression and mental health issues is not an isolated individual phenomenon, it is triggered by many psycho-social factors and mostly related to the wider social environment as individuals are influenced by the context in which they embedded. As Malaysia has become increasingly part of the competitive and globalised society, the young are bearing the brunt of the transition from one form of society to another. As discussed earlier, the transitional changes from adolescent to adulthood is not just biological, but also psychosocial and cultural. Adnam [14] attributed the mental health status of our young people to the diminishing protecting factors namely family and religion. He argued that when family and religion are no longer sufficiently serving as normative protection, the effect on individuals are detrimental. The young are especially vulnerable. After emerging from adolescence stage when rapid changes in cognitive, physical and psychosocial development take place, they continue to grow in the development of sense of self and identity. As the post-adolescence or emerging adult stage has been prolonged, they have more space and longer time to explore who they are and what they want to become in life [16]. Confusion and lost occur when they fail to achieve this development task. The conceptualization of what is meant by emerging adults where being able to be self-sufficient and individualized qualities are emphasized was mainly from a westernized society. Besides the many unpredictable variability and diversity [1], [9], Malaysian youth need to cope with the role expectation from family and society. This is reflected by their negative emotions shared by the participants when they could not meet the expectation from their parents. Studies by Shamsuddin and his team [18] have found that university students in Malaysia are having enormous stress during first year of university. Therefore they concluded that depression is prevalent symptom among university student.

The triggering event of depression in this study was related to coping with transitional changes as a result of leaving home or entering into new relationship. This was consistent with Mackinon and his associates (2014) [19] finding that entering universities is a highly stressful and developmentally important stage at which depressive symptoms can be expected. Because young people are still developing their coping skills, they feel inadequate when faced with challenging life events (in cases like a breaking up of a relationship or coping with grief and loss). Helping young people to develop positive attitudes and problem solving skills are important. Ms. A shared that she later realised she shouldn't have internalised the negative comments imposed by her boy friends which she attributed to her lack of adult skills and her immature handling of relationships at a young age. The recovery journal of our research participant was possible with the help of health care professional and supports from friends and family members. It is therefore essential to highlight the vulnerability of this emerging adult stage. As a result of social change and the lengthening of exploration of this emerging adult stage, our young people are expected to be successful in their studies and relationship, and even accepting negative events that happened to them or loved ones. With the diminishing of clear structural guidance from a wider context, they feel lost and their mental health was affected. It is important for all those responsible for young people be aware of these challenges. Emerging adulthood is a developmental stage where our young people are still in a process of learning to develop mature skills in order to be able to handle life challenges more effectively, so it will be good for all stakeholders to work together towards preventative and intervening collaboration.

\section{CONCLUSION}

Human are constantly in a state of transition, this is particularly true for emerging adults as they need to cope with the changes within their developmental stage and also the challenges in a forever changing world. For those unable to cope with those changes, their mental health will be affected. This study reveals some of the triggering events of depression, and the vulnerability of emerging adults is highlighted. Life transition for the mental health of emerging adults deserves more scholarly research especially its effects on diversity of cultures so that the challenges faced by the young in highly industrialized or post-industrialized countries will be better understood.

\section{ACKNOWLEDGMENT}

Firstly, this study was sponsored by UTAR Research Fund. Secondly, I would like to express our gratitude to all the 
research participants who have shared their life experience with me, and also Mr Lai W. Y. who has helped in the data collection.

\section{REFERENCES}

[1] J. J. Arnett, "Emerging adulthood: a theory of development from the late teens through the twenties," American Psychologist, vol. 55, no. 5, pp. 469-480, 2000

[2] K. Joyner and J. R. Udry, "You don't bring me anything but down: adolescent romance and depression," Journal of Health and Social Behaviour, vol. 41, no. 4, pp. 369-391, 2000.

[3] P. K. Kerig, "For better or worse: Intimate relationships as sources of risk or resilience for girls' delinquency," Journal of research on adolescence, vol. 24, no. 1, pp. 1-11, 2014.

[4] S. S. Rosenfield and D. Mouzon, Gender \& Mental Health, In Handbooks of Sociology \& Social Research, Chapter 14, 2013, pp. 277-296.

[5] B. Soller, "Caught in a bad romance adolescent romantic relationships and mental health," Journal of health and Social Behaviour, vol. 55 , no. 56,2014

[6] J. K. Kok, C. C. Gan, and L. Y. Goh, "Youth talk about death: causes for suicide," International Journal of Social Science and Humanity, vol. 1, no. 2, pp. 145-149, 2011.

[7] E. H. Erikson, Identity: Youth and Crisis, New York: Norton, 1968.

[8] G. S. Hall, Adolescence: Its Psychology and Its' Relation to Physiology, Anthropology, Sociology, Sex, Crime, Religion, and Education, NJ: Prentice-Hall, Englewood Cliffs, ch. 1, 1904.

[9] J. J. Arnett, "Conceptins of the transition to adulthood among emerging adults in American ethnic groups," New Directions for Child and Adolescent Development, vol. 100, pp. 63-75, 2003.

[10] Malaysia Demographics Profile. (2013). [Online]. Available: http://www.indexmundi.com/malaysia/demographic s_profile.htm

[11] New Straits Times. (May 27, 2012). Is it better being single? [Online]. Available: $\quad$ http://www.nst.com.my/nation/general/is-it-better-b eing-single-1.88064

[12] A. R. Ahmed and A. D. Hamoud, "Prevalence and associated factors of emotional disorder among Malaysian university students," International Journal of Collaborative Research on Internal Medicine \& Public Health, vol. 4, no. 7, pp. 1401-1411, 2012.
[13] Institute for Public Health, "National health and morbidity survey 2011 (NHMS 2011),” Non-Communicable Diseases, Kuala Lumpur: Institute for Public Health, vol. II, 2008.

[14] Wong. (2011, February 10). Interview with Adnan. The Stars. [Online]. Available: http://www.thestars.com.my

[15] J. A. Smith, "Reflecting on the development of interpretative phenomenological analysis and its contribution to qualitative research in psychology," Qualitative Research in Psychology, vol. 1, no. 1, pp. 39-54, 2004

[16] J. W. Santrock, Adolescence, New York: McGraw Hill International Edition, 2010.

[17] L. P. Richardson and R. Katzenellenbogen, "Childhood and adolescent depression: the role of primary care providers in diagnosis and treatment," Current Problem Pediaticr Adolescence Health Care, vol. 35 , pp. 1-24, 2005

[18] K. Shamsuddin, F. Fadzil, W. S. W. Ismail, S. A. Shah, K. Omar, N. A. Muhammad, and R. Mahadevan, "Correlates of depression, anxiety and stress among Malaysian university students," Asian Journal of Psychiatry, vol. 6, no. 4, pp. 318-323, 2013.

[19] S. P. Mackinnon and S. B. Sherry, "Perfectionism, friendship intimacy, and depressive affect in transiting university students: A longitudinal study using mixed methods," Canadian Journal of Behavioural Science, vol. 46, no. 1, pp. 49-59, 2014.

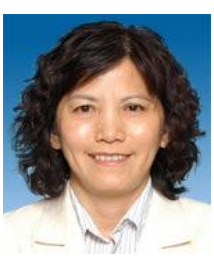

Jin Kuan Kok was born in Malaysia. She received BA in Chinese Literature from National Taiwan University, master degree in education (guidance and counselling), Durham University, England, UK, doctorate degree in education, Durham University, England, UK

She has extensive counselling experience working with young people and family. Her present professional occupation is an assistant professor, Department of Psychology and Counselling, Faculty of Arts and Social Science, Universit Tunku Abdul Rahman.

Dr. Kok is the principal researcher for many projects for the Centre of Applied Psychology at UTAR and her research interests are narrative inquiry, teenage suicide and depression, narrative approach in counselling and youth studies. 